\title{
The Fraud of Open Access Publishing
}

Opinion

\author{
S C LAKHOTIA* ID \\ Cytogenetics Laboratory, Department of Zoology, Banaras Hindu University, Varanasi 221 005, India
}

(Received on 15 February 2017; Revised on 27 February 2017; Accepted on 01 March 2017)

The nature and modalities of scientific research publications have undergone many changes during the past 4-5 decades so much so that young researchers who have recently initiated their career may find the earlier followed practices as very strange. The manuscript submission system moved from sending 3-4 manually typed copies through postal services to attaching manuscript files with email to editor and finally to impersonal online-submission platforms. The availability of the scholarly work to interested readers has also changed from reading the hard-copy version that had to be physically available in hands of the reader to the option of hard or soft-copy availability, the latter being physically available in one's computer or being virtually available somewhere on the worldwide-web of internet. In parallel, the publication strategies too have undergone great changes. Originally, scholarly works were published mostly by learned societies/academies and universities with very limited commercial interests. Gradually, however, commercial houses became the major players and this led to research publication system transforming into an industry. This of course entailed greater cost to the reader or to his/her institution. In earlier times, while a few journals levied modest page or colorprinting charges on authors, most journals provided "attractions" to the authors in the form of free issues and/or reprints, besides not levying page charges and/ or color reproduction charges. The page/color charges could also be waived off by the editor/publisher if the authors did not have resources to pay. It is interesting to note that during the later quarter of last century, some countries instituted regulations about payment of publication charges to journals. Interestingly, the publishers and the academic research establishments

\footnotetext{
*Author for Correspondence: E-mail: lakhotia@bhu.ac.in
}

found a simpler way out for payment of the publication charges by formally declaring the given paper to be an "advertisement", only for the purpose of complying with the existing regulations!

With increasing commercial interests, the authorfriendly frills disappeared rather rapidly. As the numbers of researchers wanting to publish their scholarly work increased across the globe, the numbers of willing readers to have access to latest research publications also increased. With the cost of publication increasing, due to general inflation as well as greater numbers of issues required to be published with attractive getup, many of the academic institutions (universities, societies or academies) found it increasingly difficult to sustain their research journals through individual and institutional subscriptions. Consequently, the share of commercial publication houses escalated, accompanied by rather uncontrolled increase in subscription charges for journals. This forced institutions to reduce their journal subscription profiles. With increasing availability and popularity of internet during the last 2-3 decades, hard-copies lost their primacy to the reality of virtual world. However, the expectation that soft-copies would reduce the costs to permit a greater number of institutions to subscribe to a bigger basket of journals for its members did not materialize. This happened largely because of increasing roles of cartels of publishers who dictated the market trends. The subscription costs maintained their upward trend, which deprived many readers a timely access to published research. Readers in the developing and under-developed countries and lessendowed academic institutions were most affected because of limited funds for institutional or personal subscription as well as poor internet access. 
During this transformation of the research publication process, another thing that changed was the practice of sharing of the hard-copy reprints by authors with desiring readers. Sending a postal mail reprint-request and getting the hard-copy reprint through the postal services would take a few months, yet it worked in most instances. One would have expected that with email system becoming more and more commonly used, requesting pdf file of a paper from the author should have been an easy, swift and inexpensive alternative. However, this simple and efficient possibility did not become a common practice. Rather a general impression was created that due to increasing cost of journals and copy-right issues, a large number of researchers remain deprived of learning about the new developments. It is paradoxical that in today's world of addictive use of social media where people exchange all kinds of information, researchers did not take up to exchanging pdf files of their published or unpublished work. The copy-right transfer forms that we all sign while publishing a paper, often without reading it, do not, and cannot, restrict academic exchange of published work in hard or soft-copy form.

Ostensibly to provide access to a larger readership, the idea of providing 'open access' to the published scholarly work to any reader was mooted and very widely promoted. Under this model, the author or his/her institution pays a certain charge to the publisher so that any reader across the globe has free access to the published work. This model was quickly adopted by many commercial and several notfor-profit academic publishers. Many new establishments also quickly came into being for publishing research work exclusively under the open access system. This model, where the author or institution pays for publication of its research work so that others can read it free, is of course reverse of the old practice where the author was 'rewarded' in the form of free issue or reprints while the reader/ institution paid for its access. A novel alternative that has been introduced and practiced by commercial publishers is the 'pay-per-view' model where the reader pays for each access to a soft copy of the given published article.

The 'open access' model has been widely hailed as the solution for wider availability of research findings across the globe in the internet era. However, despite the publicity given to this as a reader-friendly model which would reduce the gap between accessibility of new research to developed as well as not-so-developed countries, the experience during the past decade or so has been rather opposite. It has now become clear that only those researchers or institutions that have sufficiently rich funding can afford to publish under this model since the 'open access' charges levied by journals are very high, and, therefore, beyond the reach of a majority of researchers across the world (Gadagkar, 2008). The 'impact-factor' bug has added to this inequality. Generally, higher the impact factor, higher are the open access and other charges (submission/handling charges, page charges, color charges etc). Together, the high costs of such publications preclude an average researcher, often with sub-critical funding, from publishing in the so-called 'high-impact' journals and therefore, the vicious circle of poor-funding and 'poorimpact' publications continues (Gadagkar, 2008; Lakhotia, 2003, 2015).

An argument in support of the open access charge is that commercial houses, who now seem to have near-monopoly in scholarly research publications, have to earn profits to keep them in their business. Many of the academic societies and universities, which publish scholarly journals, have also joined the bandwagon to charge authors for 'open access'. It is not convincing that the hefty 'open access' charges that authors pay for publishing their results meet only the actual cost: the profit margins enjoyed by the publishers seem to be unreasonably high. As the Editor-in-Chief of the Proceedings of the Indian National Science Academy, I have estimated the average cost per published article in hard and softcopy formats of this journal to be less than US\$ 500 . This journal is published in hard-copy besides being freely accessible through the net and does not levy any page or color or open access charges to authors. This cost is less than $15-20 \%$ of the costs of publication publicly announced by some of the open access journals started by academic bodies (Patterson and McLennan, 2016). It appears, therefore, that many of the open access publishers make good money while the authors' pockets get lighter! As I have argued earlier (Lakhotia, 2014a), the academies, leaned societies and universities have societal responsibility to bring out scholarly journals on a no-profit basis so 
that they remain within the reach of all researchers, irrespective of their research funding. The present 'open access' model works against researchers from less-endowed institutions, irrespective of the quality of their research output (Gadagkar, 2008; Gadagkar, 2016).

Another, and more sinister, consequence of the 'open access' model is the appearance of an unusually large number of predatory journals and predatory publishers (Beall, 2012, 2013; Lakhotia, 2015) that publish 'anything' for a fee (Bohannon, 2013), which is often negotiable depending upon the purchasing power of the author. Apparently, there are many who need to publish 'something' to 'improve' their academic profile and the predatory publishers make good money by capitalizing on this need (Lakhotia, 2015). Such authors do not want to go through the peer-review process and find the 'pay- and-publish' practice very convenient. The 'more-the-merrier' scenario for assessment of quality of research has fuelled the mush-rooming of open access predatory journals across the globe, especially more so in India.

Many of the reputed and so-called high-impact journals also appear to have taken advantage of this situation through promotion of sister open access journals. These high-impact journals reject a substantial proportion of the submitted manuscripts for one or the other reason/s but at the same time persuasively encourage authors to submit or transfer the same manuscript to their open access journal which levies one or the other charges for publication. Many of these secondarily submitted or transferred manuscripts often succeed in getting published after the author has shelled out the non-trivial open access and/or other publication charges. The transformation of a manuscript unworthy of publication in the first instance to become good enough to be published in another journal of the same organization after payment of the fee raises questions.

Governmental agencies have also fallen prey to the tricks of open access publication system. Since authors find it difficult to pay the hefty charges demanded and dictated by the publication houses, an arrangement has been arrived at so that the funding agency meets the costs of publication of results coming out of its research funding. Madhan et al. (2017) have recently estimated that India is potentially spending about US\$ 2.4 million per year on open access journals and that the amount would be much more if the article processing charges paid to make papers published in hybrid open access journals are also taken into account. This obviously means that substantial amounts that could have been available to support more research, actually end in the coffers of publication houses. Since a large fraction of the open access articles do not have typical copyright issues, some 'smart' but unscrupulous publishers have published so-called collections of scholarly open access articles in one compilation to make the same available to readers on payment of charges (Poynder, 2017).

In a different approach, established and wellknown scientists are sometimes paid to contribute to a given journal so that the journal's and/or institution's impact gets boosted. Rewards by the host institution to its faculty for good research publications/outcomes is one thing, but being commissioned by a journal on paid basis for contributing to the journal does not appear to be healthy by the conventional academic practices. This practice may also degenerate like the scam of open access and predatory journals.

I maintain that scholarly publications should largely remain the responsibility of academies, learned societies and academic institutions and these should not be reduced to a source of earning (Lakhotia, 2014a). It is a societal responsibility to not only promote good research but also to make the scholarly outcome available to all, irrespective of their purchasing power. The open access system of research publications needs to be stopped. As also argued recently by Madhan et al. (2017), the funding agencies should not pay for publication charges since doing that would negate possible support to many other researchers in the research-funds-starved situation that we face. Instead, we need to encourage institutional and national repositories where soft copies of research publications are maintained and made available to all interested readers without any charge. Exchange of pdf files is easy, fast and without any extra cost and without violating the copyright issues. We need to make good use of this mode, and stop paying the open access charges or the pay-per-view charges so that the limited available resources are used for funding actual research rather than enriching the commercial publishing houses. 
We need to urgently curb the common practice of quantification of research output through some arithmetic numbers as this promotes the "publish-orperish' scenario, the root cause for such unethical

\section{References}

Beall J (2012) Predatory publishers are corrupting open access Nature 489179

Beall J (2013) Predatory publishing is just one of the consequences of gold open access Learned Publishing 26 79-84 doi: $10.1087 / 20130203$

Bohannon J (2013) Who's afraid of peer review Science 342 6065 doi: $10.1126 /$ science. 342.6154 .60

Gadagkar R (2008) Open-access more harm than good in developing world Nature 453 450-450 doi: 10.1038/ $453450 \mathrm{c}$

Gadagkar R (2016) The 'pay-to-publish'model should be abolished Notes Rec 20160039 doi: 10.1098/rsnr.2016. 0039

Lakhotia S C (2003) The vicious circle of poor science, poor journals and poor recognition Curr Sci 85 20-22

Lakhotia S C (2014a) Societal Responsibilities and Research conditions. Together, such practices have denied the serious researchers the pleasure of publication of novel findings (Lakhotia, 2014b).

Publications Proceedings of the Indian National Science Academy 80913 doi: 10.16943/ptinsa/2014/v80i5/47963

Lakhotia S C (2014b) Why we publish, where we publish and what we publish? Proc Indian Natn Sci Acad 80 511-512 doi: 10.16943/ptinsa/2014/v80i3/8

Lakhotia S C (2015) Predatory journals and academic pollution Current Science 108 1407-1408

Madhan M, Kimidi S S, Gunasekaran S, Arunachalam S (2017) Should Indian researchers pay to get their work published? Current Science 112 703-713

Patterson M, McLennan J (2016) Inside eLife: What it costs to publish. In: https://elifesciences.org/elife-news/inside-elifewhat-it-costs-publish

Poynder R (2017) Copyright: the immoveable barrier that open access advocates underestimated. In: http://poynder. blogspot.in/2017/02/copyright-immoveable-barrier-thatopen.html. 